\title{
Night-time cough in children with acute wheezing and with upper respiratory tract infection
}

\section{*Jacob Urkin a,f, Yaron Ishaya, Natalya Bilenko a,b,c,e, Yair Bar-David a,f, Eli Gazala a,f, Analia Mijalovsky ${ }^{\text {aff }}$, Vladimir Lapidus $^{\mathrm{d}}$}

${ }^{a}$ Faculty of Health Sciences, Ben-Gurion University of the Negev, Beer-Sheva, Israel

${ }^{b}$ Department of Epidemiology and Health Services Evaluation, Ben-Gurion University of the Negev, Israel

c The S. Daniel Abraham International Center for Health and Nutrition, Ben-Gurion University of the Negev, Israel

${ }^{d}$ Department of Electrical Engineering and Computing, Ben-Gurion University of the Negev, Israel

e Ministry of Health, Southern District, Beer-Sheva, Israel

${ }^{f}$ Clalit Health Services, Southern District, Beer-Sheva, Israel

Received 19th February 2008; revised 1st May 2008; accepted 6th May 2008; online 17th July 2008

\begin{abstract}
Aims: To evaluate night-time cough patterns in children with either acute wheezing or, $\mathrm{B}$ URTI, and to correlate them to the clinical diagnosis.

Methods: Night-time cough variables of 49 children diagnosed with acute wheezing and with URTI were compared using a portable cough monitoring instrument placed in the child's room.

Results: Children with acute wheezing had significantly more coughsper nightra longer duration of cough sounds, a higher number of coughing bouts per night, and a higher number of coughs per second within a bout, than children with an URTI. Children with acute wheezing coughed significantly more between 23.00 and 01.00 , whereas between 01.00 and 06.00 there was no significant difference in the number of coughs between the two groups.

Conclusions: Significant differences were found ingight-time cough variables between children with an acute episode of wheezing and children with an URTI. This could be useful in clinical practice.

(C) 2008 General Practice Airways Grouip. All rights reserved.

J Urkin, et al. Prim Care Resp J 2008; 17(4): 217-221.

doi:10.3132/pcri.2008.00038
\end{abstract}

Keywords cough recording, home monitoring, nocturnal cough, temporal cough-analysis, wheezing

\section{Introduction}

A limited number of studies describe objective cough variables in healthy and sick children. A study by Munyard and Bush' demonstrated an average of 11.3 coughs per 24 hours in healthy primary school children, with rare nocturnal cough, and Chang et al. recorded an average of 10 coughs/day in healthy children. ${ }^{2}$

Cough is a frequent symptom in children with acute wheezing (asthma and bronchiolitis) as well as in children with an upper respiratory tract infection (URTI). ${ }^{3,4}$ Although an acute episode of wheezing is heralded by cough, ${ }^{5}$ the clinical value of cough is limited, since its frequency does not correlate well with disease severity or with deterioration in lung function. ${ }^{6,7}$ Cough related to acute wheezing and to URTI may worsen at night, when there is limited ability for its objective assessment. Objective evaluation of pediatric asthma at home, using a peak flow meter, is limited by the inability of toddlers to use the device properly, is dependent on the will and effort of the child, and cannot be performed on a sleeping child. Quantitative evaluation of cough is also difficult. Cough questionnaires for parents are inaccurate and are plagued with recall bias.,9 Differentiation between cough associated with acute wheezing and cough associated with an URTI could help in making an accurate diagnosis.

\footnotetext{
* Corresponding author: Dr Jacob Urkin, Primary Pediatric Care Unit, Division of Community Health, Faculty of Health Sciences, Ben-Gurion University of the Negev, P.O. Box 653, Beer-Sheva 84105, Israel. Tel: 972-8-6477480 Fax: 972-8-6477636; E-mail: medcad@bgu.ac.il
} 
A USA recommendation regarding cough evaluation expressed the need for cough counting over many hours, using a reliable, accurate, non-invasive, and portable computerised methodology that can function unattended within a patient's home environment. ${ }^{10}$ Currently, most objective cough monitors are based on cough recording, with or without the additional measurements of chest electromyogram or video recording. ${ }^{11-15}$ Monitors that include a microphone or electrodes attached to the patient's skin are limited by the inconvenience imposed on the patient, by restriction of body movements, and by the risk that the attached device may fall off. Most of the studies that employed cough monitors were conducted in adults.

In this preliminary study we used a portable cough monitoring instrument, based on a voice recorder and a microphone, located in the patient's room at home, with software that analyses the temporal variables of cough signals. We evaluated cough patterns in children with URTI or with acute wheezing (with or without an accompanying URTI), and correlated them with the clinical diagnosis. Our hypothesis was that children with an acute wheezing attack experience more coughing episodes during the night and especially towards morning, compared to children with an acute URTI.

\section{Methods}

\section{Patients}

Subjects were selected from those children who Disited community pediatric clinics between Decemben 2003 and February 2005. Acute wheezing and URTI Were theodinical inclusion diagnoses, based on the following clinical criteria: acute wheezing - acute respiratory difficulty in a child who currently has expiratory wheezing and cough; URTI - acute illness, with runny nose and cough but no signs of bacterial complications such as pneumonia, sinusitis, or otitis media, with or without fever. Because URTI is a common provocation of asthma and bronchiolitis, children with acute wheezing with accompanying URTI were included in the wheezing group.

The treatments for acute wheezing and for URTI were based on the physician's discretion. Exclusion criteria were patients who needed antibiotics or who were treated with cough suppressants, and any chronic condition associated with cough, except asthma.

\section{Equipment}

The cough recorder, monitor, and analyser is capable of recording cough sounds continuously over more than 12 hours. One sub-unit contains the audio acquisition and prefiltering functions. It is installed on a laptop computer, and thus can be placed in a patient's home. The microphone is not attached to the patient. The unit is able to eliminate environmental noises and record only cough and cough-like sounds. Capacity is limited only by computer memory. A second sub-unit eliminates cough-like noises. The instrument was found to have a sensitivity of $98 \%$ in recognising cough sounds; however, the false positive rate was $17 \% .{ }^{16}$ In our study, a technician examined all the audiograms and removed cough-like sounds, thus eliminating the false positive signals.

\section{Study procedure}

Permission to record the child's cough sounds at home was obtained from the parents on the night following the enrolment. A laptop computer with the installed coughrecorder and analyser was placed near the child's bed. Recording was pre-set to start at 23.00 and to stop at 06.00 , assuming that during these hours the child was asleep.

The electronic recordings were displayed on the computer screen as phonograms, coupled with the audible corresponding sounds. Signals that were not recognised by the human ear as coughs while examining the audio recording were excluded.

\section{Data analysis}

Analysis was based on defipitions of cough, coughing bout, cough latency, and distribution of these variables along the time axis. 'Cough Wwas defined as a single sound, short and abrupt, as redognised by a human observer; this is the result of a sipgle abrupt opening of the glottis, following an increase in thoracic pressure. A single cough can easily be recognised by looking at a phonogram. A 'coughing bout' was defined as a sequence of cough sounds with Ointerruptions of up to one inspiration at a time. A bout may have any number of single inspiration breaks. 'Cough latency' was defined as the time from the end of the last cough or bout to the beginning of a new bout or single cough, as long as that period was more than four seconds long. The rationale for this definition is that a patient is able to inspire twice in the time period of four seconds, thus making the following cough a new bout. This definition is similar to the one used by Davies et al. ${ }^{17}$

Measurements of coughs, bouts, cough latencies, and their length and time of occurrence, were performed by the computer with an accuracy of one centile of a second. Statistical analysis was conducted using SPSS software. Standard nonparametric (chi-square) and parametric (t-test and ANOVA) statistics were run to compare cough patterns, clinical diagnosis and demography. A $p$ value $<0.05$ was considered statistically significant.

The study was approved by the institutional research review board. Parental informed consent was requested by the primary pediatrician after the conclusion of a clinical encounter where an acute wheezing episode or an URTI was diagnosed.

\section{Results}

\section{Population}

Sixty-nine children were recruited. Twenty children were not 
Table 1. Gender, mean age, and duration of illness of children with acute wheezing* and with URTI.

\begin{tabular}{lccc} 
& Wheezing & URTI & Total \\
\hline Patients $(\mathrm{n}[\%])$ & $27(55.1)$ & $22(44.9)$ & $49(100)$ \\
Male $(\mathrm{n}[\%])$ & $14(51.9)$ & $14(63.6)$ & $28(57)$ \\
Age in years (mean \pm SD) & $4.0 \pm 2.0$ & $3.7 \pm 1.5$ & $3.9 \pm 1.8$ \\
$\begin{array}{l}\text { Duration of illness } \\
\text { in days (mean } \pm \text { SD) }\end{array}$ & $3.03 \pm 1.9$ & $3.68 \pm 2.10$ & $3.32 \pm 2.02$ \\
\hline
\end{tabular}

(No significant differences found)

* In the wheezing group $40.7 \%$ had also URTI symptoms

included in the data analysis due to technical problems: four moved to another room during the night; in four cases there was power failure or an unplugged microphone; and in 12 cases (6 in each group) no cough was recorded. The remaining 49 children constituted the study population. The mean age, gender, duration of illness, and clinical diagnosis of participating children are summarised in Table 1.

In the wheezing group, 11 of the 27 children (40.7\%) had signs of an URTI as well. Based on physicians' clinical judgment, $13(48.1 \%)$ children had mild and 14 (51.9\%) had moderate respiratory distress. Eight children $(29.6 \%)$ in the wheezing group and 12 (54.5\%) children in the URTI group had fever.

\section{Cough analysis}

A total of 4910 coughs (1409 bouts) were included in the final analysis, 3406 coughs (987 bouts) in the wheezing group and 1504 coughs (423 bouts) in the URTI group.

The analysis of coughs and bouts along the time axis is summarised in Table 2. There was a significant statistical difference between the two clinical groups in terms of the number of coughs, the total duration of cough sounds per child in seconds, the number of bouts per child, and the number of coughs per second within a bout. There was no statistical difference in the number of coughs per bout and the duration of bout per child in seconds.

The temporal distribution of the number and duration of coughs per hour is presented in Figures 1 and 2. Children in the wheezing group coughed significantly more times than children in the URTI group between 23.00 and midnight $(26.22 \pm 42.05$ and $5.64 \pm 742$, respectively, $p<0.001)$, as well as between midnight and 01.00, $(29.00 \pm 38.87$ and $4.36 \pm 9.79$, respectively, $p<0.001)$. The mean duration of coughs penchild between 23.00 and midnight was $25.26 \pm 47.51$ seconds in the wheezing group and $4.40 \pm 6.19$ seconds in the URTI group $(p<0.05)$. Between midnight and

Table 2. Cough variables in children with acute whelezing* and with URTI.

\begin{tabular}{|c|c|c|c|c|}
\hline & & $\begin{array}{l}\text { Wheezing } \\
n=27\end{array}$ & $\begin{array}{l}\text { URTI } \\
\mathrm{n}=22\end{array}$ & $p$ value \\
\hline $\begin{array}{l}\text { Number of coughs per child } \\
\text { (per night) }\end{array}$ & $\begin{array}{l}\text { mean } \\
\text { range } \\
\text { median }\end{array}$ & $\begin{array}{c}126.15 \pm 103.04 \\
24-469 \\
90\end{array}$ & $\begin{array}{c}68.40 \pm 62.42 \\
15-222 \\
44\end{array}$ & 0.026 \\
\hline $\begin{array}{l}\text { Total duration of cough-sounds } \\
\text { per child (seconds) }\end{array}$ & $\begin{array}{l}\text { mean } \\
\text { range } \\
\text { median }\end{array}$ & $\begin{array}{c}124.19 \pm 112.34 \\
24.78-503.97 \\
87.87\end{array}$ & $\begin{array}{c}51.22 \pm 47.39 \\
6.65-169.8 \\
36.98\end{array}$ & 0.007 \\
\hline Number of bouts per child & $\begin{array}{l}\text { mean } \\
\text { range } \\
\text { median }\end{array}$ & $\begin{array}{c}36.55 \pm 27.89 \\
4-115 \\
30\end{array}$ & $\begin{array}{c}19.22 \pm 15.79 \\
2-60 \\
16\end{array}$ & 0.013 \\
\hline Number of coughs per bout & $\begin{array}{l}\text { mean } \\
\text { range } \\
\text { median }\end{array}$ & $\begin{array}{c}3.79 \pm 1.51 \\
2-7 \\
3\end{array}$ & $\begin{array}{c}3.64 \pm 1.94 \\
2-11 \\
3\end{array}$ & n.s. \\
\hline $\begin{array}{l}\text { Duration of a bout per child } \\
\text { (seconds) }\end{array}$ & $\begin{array}{l}\text { mean } \\
\text { range } \\
\text { median }\end{array}$ & $\begin{array}{c}3.74 \pm 1.77 \\
1.36-7.16 \\
3.19\end{array}$ & $\begin{array}{c}2.96 \pm 2.33 \\
1.01-10.47 \\
2.31\end{array}$ & n.s. \\
\hline $\begin{array}{l}\text { Number of coughs per second } \\
\text { within a bout }\end{array}$ & $\begin{array}{l}\text { mean } \\
\text { range } \\
\text { median }\end{array}$ & $\begin{array}{c}1.07 \pm 0.24 \\
0.74-1.57 \\
0.24\end{array}$ & $\begin{array}{c}1.36 \pm 0.30 \\
0.61-1.83 \\
1.36\end{array}$ & $<0.001$ \\
\hline
\end{tabular}

* In the wheezing group $40.7 \%$ had also URTI symptoms 


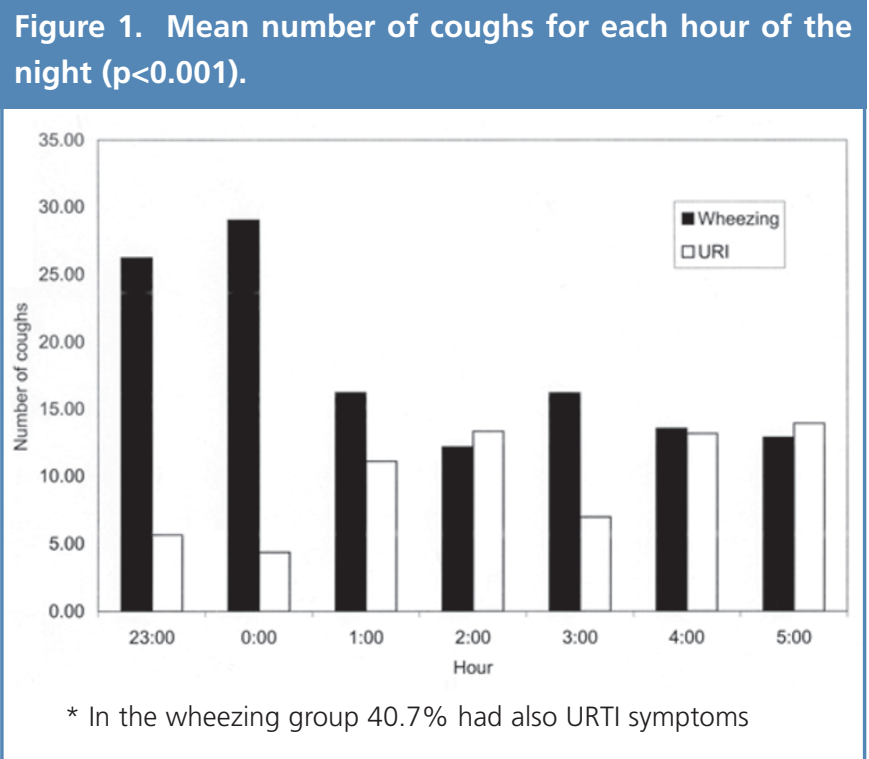

01.00 the respective measurements were $32.51 \pm 46.09$ versus $3.10 \pm 7.45$ seconds $(p<0.005)$. Between 01.00 and 06.00 there was no significant difference between the two groups.

\section{Disaussion}

Cough is a common symptom of asthma, bronchiolitis and URTI, diseases that are frequently encountered in childhood, 3,18 Trying to learn something from the nature of cough for dinical purposes poses some unresolved questions. Is cough patientdependent, or disease-dependent? What is the diurnal variation of the cough? How does age affect cough? How does treatment of the disease affect the accompanying cough? What is the correlation between cough variables and lung function tests in patients, with asthma?

It is difficult to evaluate cough in patients who are under treatment, since treatment may affect cough variables. However, medico-ethical considerations prevent the study of patients without providing the appropriate treatment. Research on respiratory parameters in small children is limited by their inability to perform lung function tests or peak expiratory measurements. The study of night-time cough has additional limitations, since it may not resemble daytime cough due to diurnal changes in lung physiology and home environmental cough triggers. ${ }^{19,20}$

There is a scarcity of objective information regarding the status of the disease outside the physician's office. Measuring cough and using its variables as a tool for diagnosis and management of disease is beyond the reach of today's clinician. This is due to a lack of easy-to-use measuring equipment and to limited research that correlates clinical variables and cough measurements in order to produce a useful practical paradigm. This study tries to fill the gap by looking at night-time cough and coughing bouts in children
Figure 2. Total duration of coughs per hour for each hour of the night $(p<0.05)$.

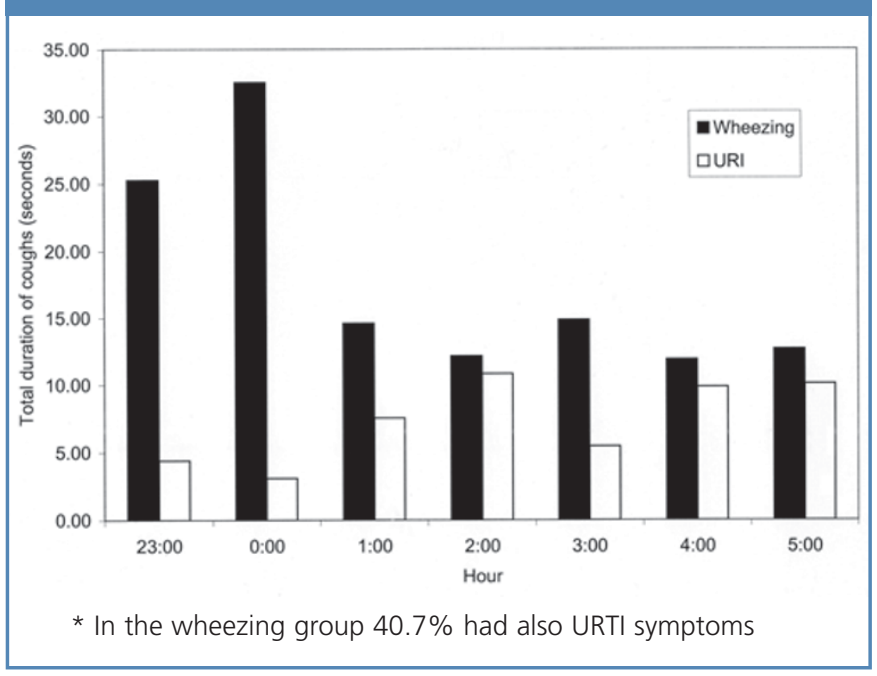

with either an acute episode of wheezing or an URTI.

Studies using cough questionnaires have documented poor agreement between reported and recorded nocturnal cough in asthma. ${ }^{8,9}$ Automatic cough measurements seem to be a better solution. Cough measuring instruments have been described by many researchers. Most were tested in adults in laboratory conditions. ${ }^{11-15}$ Cough monitoring instruments that include devices attached to the subjects have major limitations, since the devices tend to fall off or restrict normal behavior. Studies in children are even more difficult to perform for lack of cooperation. The cough monitoring instrument used in our study does not have these limitations, since it uses a microphone placed in the room. The recording device is installed in a laptop computer and thus is easily placed in the patient's room for overnight recording.

Our study demonstrates some fundamental differences between the night-time cough of children with an URTI and the cough of children with an acute episode of wheezing with or without accompanying URTI. Children with acute wheezing had more coughs at night, the total duration of time taken by coughs was longer, and they had more coughing bouts. The most striking difference was in the number of coughs per second within a bout. In children with acute wheezing, the time interval between coughs within each bout was much longer. This is probably related to a general restriction in air movement. This finding could be used as a clinical clue to the diagnosis of asthma if automated cough monitoring were to become regular practice.

The study demonstrates that children with acute wheezing coughed significantly more around midnight, whereas children with an URTI had the least cough events at that time of night (Figure 1). During other hours of the night the children with acute wheezing coughed less, whilst the 
children with an URTI coughed more, with no significant difference between the two groups. This finding challenges the accepted clinical impression that patients with asthma cough more towards the morning. We believe that this impression is true in patients with poorly controlled asthma, secondary to the physiologic decline in lung function toward morning. The patients in our study presented with an acute episode of wheezing that required intensive treatment the evening before recording. This treatment, which included corticosteroids, did not become fully effective around midnight but rather later, towards morning. This probably explains why the patients with acute wheezing coughed more in the early hours of the recording than in the later hours.

As URTI is one of the conditions that provokes acute wheezing, it is not surprising that $40.7 \%$ of the children had both. By including these children in the wheezing group we took the risk of narrowing the differences between the two study groups. The demonstrated significant differences suggest that the differences in cough variables between children with acute wheezing, without URTI, and children with URTI who are not wheezing, are even greater. However, it is possible that children with acute wheezing with URTI cough more than children with purely acute wheezing. Since this is a preliminary study on a small number of participants we could not clarify this point.

One of the limitations of this type of study is the dependence upon an electronic instrument that max have technical problems. Not being attached to the patient is sometimes a drawback, particularly since cough is not recorded when the child leaves, the rooms Also, the instrument does not eliminate other people's coughs.

\section{Condusions}

An automatic night-time cough monitoring instrument has the advantage of recording objectively precise time intervals in relation to the pattern of coughing. This instrument is more accurate and reliable than cough questionnaires. In this preliminary study, significant differences were found in nighttime cough variables between children with an URTI and children with an acute episode of wheezing with or without an URTI. This may be useful in clinical practice, but this is yet to be established. Further studies are needed to clarify the relationship between acute wheezing and cough variables. These should include patients with acute wheezing who do not have URTI symptoms. We anticipate that, in the future, clinicians will have objective, portable, miniature coughmonitoring instruments for use at home ${ }^{10,21}$ that will aid in the clinical diagnosis and monitoring of treatment of coughrelated disorders.

\section{Conflicts of interest}

None to declare.

\section{Acknowledgements}

The authors are indebted to the late Prof. Arnon Cohen, from the Department of Electrical Engineering and Computing, Ben-Gurion University of the Negev, who initiated and supervised this study. The authors would also like to express their gratitude to Ms. Nurit Barak for editorial support.

\section{References}

1. Munyard P, Bush A. How much coughing is normal? Arch Dis Child 1996;74(6):531-4.

2. Chang $A B$, Phelan PD, Robertson CF, Newman RG, Sawyer SM. Frequency and perception of cough severity. Pediatr Child Health 2001;37(2):142-5.

3. Wald ER, Guerra N, Byers C. Frequency and severity of infections in day care: three-year follow-up. J Pediatr 1991;118(4):509-14

4. Pavord ID. Cough and asthma. Pulm Pharmacol Ther 2004;17(6):399-402.

5. Chang AB, Harrhy VA, Simpson J, Masters IB, Gibson PG. Cough, airway inflammation, and mild asthma exacerbation. Arch Dis Child 2002;86(4):270-5.

6. Chang AB, Phelan PD, Robertson CF, Roberts CF, Sawyer SM. Relation between measurements of cough severity. Arch Dis Child 2003;88(1):57-60.

7. Brooke AM, Lambert PC, Burton PR, Clarke C, Lyut DK, Simpson H. Night-cough in a population-based sample of children: characteristics, relation to symptoms and associations with measures of asthma severity. Eur Respir J 1996;9(1):65-71.

8. Falconer A, OldmanC, Helms P. Poor agreement between reported and recorded nocturnal cough in asthma. Pediatr Pulmonol 1993;15(4):209-11.

9. Archer $\mathrm{LN}$, Simpson $\mathrm{H}$. Night-cough counts and diary card scores in asthma. Arch Dis Child 1985;60(5):473-4.

10. Urwin RS, Baumann, MH, Bolser DC. American College of Chest Physicians (ACCP). Diagnosis and management of cough executive summary, ACCP evidence-based clinical practice guidelines. Chest 2006;129(1 Suppl):1S-23S.

1. Munyard P, Busst C, Logan-Sinclair R, Bush A. A new device for ambulatory cough recording. Pediatr Pulmonol 1994;18(3):178-86.

12. Hsu JY, Stone RA, Logan-Sinclair RB, Worsdell M, Busst CM, Chung KF. Coughing frequency in patients with persistent cough: assessment using a 24 hour ambulatory recorder. Eur Respir J 1994;7(7):1246-53.

13. Piirila P, Sovijarvi AR. Objective assessment of cough. Eur Respir J 1995; 8(11):1949-56.

14. Pavesi L, Subburaj S, Porter-Shaw K. Application and validation of a computerized cough acquisition system for objective monitoring of acute cough: a meta-analysis. Chest 2001;120(4):1121-8.

15. Corrigan DL, Paton JY. Pilot study of objective cough monitoring in infants. Pediatr Pulmonol 2003;35(5):350-7.

16. Berman S. Characterization and classification of children's cough signals. M.Sc. Thesis, Electrical and Computer Engineering, Ben-Gurion University of the Negev, Beer-Sheva, Israel. 1995.

17. Davies MJ, Fuller P, Piccciotto A, McKenzie SA. Persistent nocturnal cough: randomized controlled trial of high dose inhaled corticosteroid. Arch Dis Child 1999;81:38-44

18. Dombkowski KJ, Wasilevich EA, Lyon-Callo SK. Pediatric asthma surveillance using Medicaid claims. Public Health Rep 2005;120(5):515-24.

19. Kelly EA, Houtman JJ, Jarjour NN. Inflammatory changes associated with circadian variation in pulmonary function in subjects with mild asthma. Clin Exp Allergy 2004;34(2):227-33.

20. Silkoff PE, Martin RJ. Pathophysiology of nocturnal asthma. Ann Allergy Asthma Immunol 1998;81(5):378-83.

21. McGarvey LP. Cough: Which investigations are most useful in the diagnosis of chronic cough? Thorax 2004;59(4):342-6.

Available online at http://www.thepcrj.org 